\title{
The prevalence of turnover intention and influencing factors among emergency physicians: a national observation
}

Shijiao Yan ${ }^{1,2+}$, Xin Shen ${ }^{3 \dagger}$, Rixing Wang ${ }^{4}$, Zhiqian Luo ${ }^{2,5,6}$, Xiaotong Han ${ }^{7^{*}}$, Yong Gan ${ }^{3 *}$ and Chuanzhu Lv, ${ }^{6,8^{*}}$

\begin{abstract}
Background: Adverse consequences of physician turnover include financial losses, reduced patient satisfaction, and organizational instability. However, no study has reported the prevalence among emergency physicians. This study explore the rate and influencing factors of this community, which could provide a reference for preventing the loss of emergency physicians.

Methods: A nationally representative cross-sectional survey of 15,243 emergency physicians was conducted in 31 provinces across China between July and September 2019. Multivariable logistic regression analysis was performed to identify predictors of turnover intention.

Results: There were $49.75 \%$ of emergency physicians having turnover intention. Logistic regression analysis model showed that emergency physicians who were male $(\mathrm{OR}=0.87)$ and older $[>37$ and $\leq 43(\mathrm{OR}=0.78)$ or $>43$ $(\mathrm{OR}=0.64)$ ], worked in eastern China $(\mathrm{O}=0.88)$ and higher level of hospital [two-grade level $(\mathrm{OR}=0.71)$ or threegrade level $(\mathrm{OR}=0.56)]$, and had high $(\mathrm{OR}=0.75)$ or middle $(\mathrm{OR}=0.81)$ level income were not more likely to have less turnover intention, while those who had higher education level [bachelor degree $(O R=1.55)$ or master degree or higher $(\mathrm{OR}=1.63)]$, long work tenure $[>3$ and $\leq 6(\mathrm{OR}=1.29)$ or $>6$ and $\leq 11(\mathrm{OR}=1.41)$ or $>11(\mathrm{OR}=1.25)]$, poorer health status [fair $(\mathrm{OR}=1.55)$ or poor $(\mathrm{OR}=2.12)$ ] and sleep quality [fair $(\mathrm{OR}=1.16)$ or poor $(\mathrm{OR}=1.43)$ ], history of coronary heart disease $(O R=1.29)$, depression $(O R=2.77)$ and experienced the shift work $(O R=1.37)$ and workplace violence $(\mathrm{OR}=1.78)$ were more likely to intend to leave.
\end{abstract}

*Correspondence: hanxiaotong2021@163.com; scswi2008@163.com; Ivchuanzhu677@126.com

${ }^{\dagger}$ Shijiao Yan and Xin Shen contributed equally to this work

${ }^{3}$ Department of Social Medicine and Health Management, School of Public Health, Tongji Medical College, Huazhong University of Science and Technology, No. 13 Hangkong Road, Wuhan 430030, Hubei, China

${ }^{7}$ Department of Emergency Medicine, Hunan Provincial Institute

of Emergency Medicine, Hunan Provincial Key Laboratory of Emergency and Critical Care Metabolomics, Hunan Provincial People's Hospital/The First Affiliated Hospital, Hunan Normal University, Changsha, Hunan,

China

${ }^{8}$ Department of Emergency Medicine Center, Sichuan Provincial People's

Hospital, University of Electronic Science and Technology of China, Chengdu, China

Full list of author information is available at the end of the article

(c) The Author(s) 2021. Open Access This article is licensed under a Creative Commons Attribution 4.0 International License, which permits use, sharing, adaptation, distribution and reproduction in any medium or format, as long as you give appropriate credit to the original author(s) and the source, provide a link to the Creative Commons licence, and indicate if changes were made. The images or other third party material in this article are included in the article's Creative Commons licence, unless indicated otherwise in a credit line to the material. If material is not included in the article's Creative Commons licence and your intended use is not permitted by statutory regulation or exceeds the permitted use, you will need to obtain permission directly from the copyright holder. To view a copy of this licence, visit http://creativecommons.org/licenses/by/4.0/. The Creative Commons Public Domain Dedication waiver (http://creativeco mmons.org/publicdomain/zero/1.0/) applies to the data made available in this article, unless otherwise stated in a credit line to the data. 
Conclusion: Nearly half of emergency physicians in China have turnover intention. Targeted intervening measures should be taken to reduce the turnover intention, so as to avoid the shortage of physicians and thus hinder the supply of emergency medical services.

Keywords: Turnover intention, Emergency medicine, Emergency physicians, Physicians shortage, Prevalence, China

\section{Background}

Turnover is the actual leaving behavior essential to human resource management of a workforce [1]. Turnover intention refers to the psychological state before turnover, which indicates that the employee is not satisfied with the job, has the idea of resigning, looks for job opportunities, evaluates and compares other job opportunities. Intention to leave (turnover intention) is about an individual's vision of a possible leaving and it often is studied as a proxy for actual turnover [2]. Previous studies have shown that work pressure, psychological problems and other factors have a significant impact on turnover intention [3, 4].

Physicians are one of the groups with high turnover intention and their turnover intention includes not only leaving the current post, but also transferring to other departments [5]. Previous systematic reviews have shown that about $3.2 \%$ to $53.7 \%$ of physicians have the turnover intention [5]. The generation of turnover intention is closely related to factors, such as work pressure and mental health [6-8], and its widespread prevalence will cause a shortage of doctors, and then produce diversified adverse results [9-12]. Specifically, the turnover of physicians threaten the operation of the health care system, may lead to the inadequate supply of health care services, thus impeding the masses' access to health care services, and even endangering the care and quality of life of patients [13-15]. In addition, adverse consequences of physician turnover include financial losses, reduced patient satisfaction, and organizational instability [16].

In providing medical services, emergency physicians are often faced with the problems of high work pressure, long shift time, large number of patients and various types of diseases; in the medical setting, they face staff shortages and the chaotic work environment characterized by unpredictability [17], especially in China. China receives the world's largest number of emergency patients each year (more than 166.5 million); China also has the largest number of emergency physicians, with nearly 60,000 , accounting for more than $2.1 \%$ of the total number of physicians [18]. However, according to previous studies, emergency physicians in China face high work pressure and complex psychological problems [19], which laid a hidden trouble for the rise of turnover intention of emergency physicians [20].
Previous research on job stress among physicians has shown that emergency physicians have higher levels of stress (over 60\%) compared to general physicians (38\%) $[21,22]$. However, it has not been reported whether emergency physicians have higher turnover intentions. Previous studies on turnover intention mostly focused on psychiatrists [23], general practitioners [24], emergency department nurses [25] and other groups. Therefore, the purpose of this study was to explore the prevalence of turnover intentions (including switching departments and turnover) of emergency physicians and influencing factors, which could provide a reference for global health-care policy makers and researchers to solve the shortage of physicians.

\section{Methods}

\section{Ethics statement}

The study protocol was approved by the Institutional Ethics Board of the Second Affiliated Hospital of Hainan Medical University, Haikou, China. All individuals provided written informed consent.

\section{Study participants and survey design}

A cross-sectional study was carried out in China from July 2019 to September 2019. A multistage stratified random sampling design was used in this study. First, a total of 31 Chinese provinces were classified as developed, developing, or less-developed regions according to per capital household income in 2018. Second, we selected 10 hospitals randomly from each province. Third, based on the number and scale of the hospitals, $40 \%$ of the emergency physicians who had practiced in the emergency department for at least 6 months were randomly selected from each hospital to complete a self-administered questionnaire. The participants included only emergency physicians and not nurses and other technicians who provided emergency care. In total, 15,455 emergency physicians were asked to participate in this survey, and 182 physicians did not respond. In addition, 30 questionnaires were discarded due to missing information. Ultimately, 15,243 eligible questionnaires were used in this analysis.

\section{Instrument and measurement}

The questionnaire was designed based on literature reviews, group discussions, and preliminary interviews. 
Furthermore, a pilot study was conducted in one Wuhan community to improve the quality of the questionnaire. This questionnaire focuses on the physical and mental health and professional attitude of emergency physicians, and the relevant parts of this study include sociodemographic information (e.g., region, age, gender, education level, marital status, and professional title), workplace violence, depression and turnover intention. The "turnover intention" section have one items, which is "Wether you have turnover intention". The answers can be either "yes" or "no".

The Chinese version of the Workplace Violence Scale (WVS) WVS was developed by Wang et al. [26], has a good reliability and validity for measuring the incidence of workplace violence when applied to medical staff in China. It includes 5 items measured with a four-point ordinal scale ranging from 0 (never) to 3 (more than 3 times/year). In this study, the Cronbach's alpha for WPV was 0.81 .

\section{The Center for Epidemiological Studies Depression scale (CES-D)}

CES-D was used to assess depressive symptoms. The scale includes include 20 items; each item is scored on a four-point scale ranging from 0 ("little or none of the time") to 3 ("most or almost all of the time"). The total score ranges from 0 to 60 points, and the higher the score is, the more severe the depressive symptoms. On the original CES-D scale, a total score of 16 was used to detect the presence of depressive symptoms [27]. However, a large number of studies have assessed the diagnostic accuracy of CES-D in detecting depression in the general population and have proposed multiple cutoff points, such as a cutoff point of 18 for elderly people living in residential homes [28] and a cutoff score of 22 for older Chinese individuals [29]. A meta-analysis systematically reviewed 28 CES-D studies, including several Chinese studies, and obtained an optimal cutoff point of 20 points [30]. As a result, an overall score of 20 or higher was considered an indicator of depressive symptoms in this study, consistent with previous research [31]. The CES-D has good reliability and validity, and it has been widely used in the Chinese population. In this study, the Cronbach's alpha coefficient of the scale was 0.90 .

\section{Data collection and quality control}

A web link to the online questionnaire, which was designed using Questionnaire Star, was disseminated to the participants through WeChat (similar to WhatsApp, WeChat is the largest communication platform in China, with over one billion users). To prevent the same participants from repeatedly answering the questionnaire, each device (e.g., smartphone or computer) was eligible to complete the questionnaire only once, and logical checks were concurrently run on the WeChat platform to identify invalid questionnaires. The data were entered into a web-based database by trained investigators to ensure accuracy.

\section{Statistical methods}

The descriptive analyses used means for the continuous variables and percentages for the categorical data. This study examines the effects of both single and multiple factors. The descriptive statistics for the categorical variables were reported as the frequency (percentage) and were compared between "yes" and "no" using Pearson's $\chi^{2}$ test. Weather having turnover intention as the dependent variables, were treated as categorical variables. Multivariable logistic analysis was used to calculate the odds ratios (ORs) and 95\% confidence intervals (CIs) for factors that might be associated with the prevalence of turnover intention. All analyses were performed using STATA 13.0, and all tests were two sided with a significance level of 0.05 .

\section{Results}

Table 1 presents the main characteristics of the survey respondents. Among the 15,243 respondents, most were married (83.26\%), were men (69.87\%) and had a bachelor's degree or above (94.18\%). The mean age (SD) was 37.66 (8.06) years. Approximately $65 \%$ of the participants had intermediate or senior professional titles. In total, $55.23 \%$ of the respondents were in the middle-income and lower income groups, more than half estimated their own health to be at the general level, and approximately $40 \%$ were currently employed in eastern China. A minority of the participants $(27.19 \%)$ participated in regular physical activity. 89.87\% of respondents reported exposure to WPV. In addition, 7584 (49.75\%) of emergency physicians had turnover intention. (Table 1).

The factors associated with the emergency physicians having turnover intention are presented in Table 2. Emergency physicians who were male $(\mathrm{OR}=0.87)$ and older $[>37$ and $\leq 43 \quad(\mathrm{OR}=0.78)$ or $>43 \quad(\mathrm{OR}=0.64)$ ], worked in eastern China $(\mathrm{OR}=0.88)$ and higher level of hospital [two-grade level $(\mathrm{OR}=0.71)$ or three-grade level $(\mathrm{OR}=0.56)]$, and had high $(\mathrm{OR}=0.75)$ or middle $(\mathrm{OR}=0.81)$ level income were not more likely to have less turnover intention, while those who had higher education level [bachelor degree $(\mathrm{OR}=1.55)$ or master degree or higher $(\mathrm{OR}=1.63)]$, long work tenure [ $>3$ and $\leq 6(\mathrm{OR}=1.29)$ or $>6$ and $\leq 11(\mathrm{OR}=1.41)$ or $>11$ $(\mathrm{OR}=1.25)$ ], poorer health status [fair $(\mathrm{OR}=1.55)$ or poor $(\mathrm{OR}=2.12)$ ] and sleep quality [fair $(\mathrm{OR}=1.16)$ or poor $(\mathrm{OR}=1.43)]$, history of coronary heart disease $(\mathrm{OR}=1.29)$, depression $(\mathrm{OR}=2.77)$ and experienced 
Table 1 Statistical description of study samples

\begin{tabular}{|c|c|c|c|c|}
\hline Variables & $N(\%)$ & Having turnover intention & $x^{2}$ & $P$ value \\
\hline Total & $15,243(100.00)$ & $7584(49.75)$ & NA & NA \\
\hline \multicolumn{5}{|l|}{ Gender } \\
\hline Male & $10,650(69.87)$ & $5443(51.11)$ & \multirow[t]{2}{*}{25.92} & \multirow[t]{2}{*}{$<0.01$} \\
\hline Female & $4593(30.13)$ & $2141(46.61)$ & & \\
\hline \multicolumn{5}{|l|}{ Age group, y } \\
\hline$\leq 31$ & $4089(26.83)$ & $1993(48.74)$ & \multirow[t]{4}{*}{168.23} & \multirow[t]{4}{*}{$<0.01$} \\
\hline$>31$ and $\leq 37$ & $4117(27.01)$ & $2309(56.08)$ & & \\
\hline$>37$ and $\leq 43$ & $3291(21.59)$ & $1714(52.08)$ & & \\
\hline$>43$ & $3746(24.58)$ & $1568(41.86)$ & & \\
\hline \multicolumn{5}{|l|}{ Region } \\
\hline Eastern China & $6000(39.36)$ & $2843(47.38)$ & \multirow[t]{3}{*}{22.25} & \multirow[t]{3}{*}{$<0.01$} \\
\hline Central China & $4097(26.88)$ & $2102(51.31)$ & & \\
\hline Western China & $5146(33.76)$ & $2639(51.28)$ & & \\
\hline \multicolumn{5}{|l|}{ Education level } \\
\hline Associate's degree or vocational diploma & $894(5.86)$ & $343(38.37)$ & \multirow[t]{3}{*}{53.39} & \multirow[t]{3}{*}{$<0.01$} \\
\hline Bachelor degree & $10,293(67.53)$ & $5249(51.00)$ & & \\
\hline Master degree or higher & $4056(26.61)$ & $1992(49.11)$ & & \\
\hline \multicolumn{5}{|l|}{ Marital status } \\
\hline Married/widow/divorced & $12,691(83.26)$ & $6342(49.97)$ & \multirow[t]{2}{*}{1.45} & \multirow[t]{2}{*}{0.23} \\
\hline Unmarried & $2552(16.74)$ & $1242(48.67)$ & & \\
\hline \multicolumn{5}{|l|}{ Income status } \\
\hline High & $1672(10.97)$ & $655(39.17)$ & \multirow[t]{3}{*}{202.06} & \multirow[t]{3}{*}{$<0.01$} \\
\hline Middle & $6746(44.26)$ & $3128(46.37)$ & & \\
\hline Low & $6825(44.77)$ & 3801 (55.69) & & \\
\hline \multicolumn{5}{|l|}{ Work tenure, y } \\
\hline$\leq 3$ & $4921(32.28)$ & $2249(45.70)$ & \multirow[t]{4}{*}{124.93} & \multirow[t]{4}{*}{$<0.01$} \\
\hline$>3$ and $\leq 6$ & $3114(20.43)$ & $1685(54.11)$ & & \\
\hline$>6$ and $\leq 11$ & $3424(22.46)$ & $1907(55.70)$ & & \\
\hline$>11$ & $3784(24.82)$ & $1743(46.06)$ & & \\
\hline \multicolumn{5}{|l|}{ Contract status } \\
\hline Permanent & $9715(63.75)$ & $4802(49.43)$ & 1.13 & 0.29 \\
\hline Temporary & $5528(36.27)$ & $2782(50.33)$ & & \\
\hline Professional title & & & & \\
\hline Elementary or below & $5349(35.09)$ & $2619(48.96)$ & 88.22 & $<0.01$ \\
\hline Intermediate & $5861(38.45)$ & $3168(54.05)$ & & \\
\hline Senior & $4033(26.46)$ & $1797(44.56)$ & & \\
\hline Ownership & & & & \\
\hline Governmental & $14,599(95.78)$ & $7272(49.81)$ & 0.46 & 0.50 \\
\hline Non-governmental & $644(4.22)$ & $312(48.45)$ & & \\
\hline Level of hospital & & & & \\
\hline Three-grade level & $10,152(66.60)$ & $4921(48.47)$ & 20.07 & $<0.01$ \\
\hline Two-grade level & $4841(31.76)$ & $2535(52.37)$ & & \\
\hline Other & $250(1.64)$ & $128(51.20)$ & & \\
\hline Shift work & & & & \\
\hline Yes & $13,288(87.17)$ & $6918(52.06)$ & 220.77 & $<0.01$ \\
\hline No & $1955(12.83)$ & $666(34.07)$ & & \\
\hline Workplace violence & & & & \\
\hline Yes & 13,699 (89.87) & 7171 (52.35) & 363.71 & $<0.01$ \\
\hline No & $1544(10.13)$ & $413(26.75)$ & & \\
\hline
\end{tabular}


Table 1 (continued)

\begin{tabular}{|c|c|c|c|c|}
\hline Variables & $N(\%)$ & Having turnover intention & $x^{2}$ & $P$ value \\
\hline \multicolumn{5}{|c|}{ Self-perceived health status } \\
\hline Good & $4707(30.88)$ & $1581(33.59)$ & \multirow[t]{3}{*}{961.79} & \multirow[t]{3}{*}{$<0.01$} \\
\hline Fair & $7729(50.71)$ & $4045(52.34)$ & & \\
\hline Poor & $2807(18.42)$ & $1958(69.75)$ & & \\
\hline \multicolumn{5}{|l|}{$\mathrm{BMI}\left(\mathrm{kg} / \mathrm{m}^{2}\right)$} \\
\hline$<25$ & $9588(62.90)$ & $4735(49.38)$ & \multirow[t]{2}{*}{1.41} & \multirow[t]{2}{*}{0.24} \\
\hline$\geq 25$ & $5655(37.10)$ & $2849(50.38)$ & & \\
\hline \multicolumn{5}{|c|}{ History of hypertension } \\
\hline Yes & $2317(15.20)$ & $1274(54.98)$ & \multirow[t]{2}{*}{29.91} & \multirow[t]{2}{*}{$<0.01$} \\
\hline No & $12,926(84.80)$ & $6310(48.82)$ & & \\
\hline \multicolumn{5}{|c|}{ History of diabetes } \\
\hline Yes & $598(3.92)$ & $308(51.51)$ & \multirow[t]{2}{*}{0.76} & \multirow[t]{2}{*}{0.38} \\
\hline No & $14,645(96.08)$ & $7276(49.68)$ & & \\
\hline \multicolumn{5}{|c|}{ History of coronary heart disease } \\
\hline Yes & $471(3.09)$ & 308 (65.39) & \multirow[t]{2}{*}{47.55} & \multirow[t]{2}{*}{$<0.01$} \\
\hline No & $14,772(96.91)$ & $7276(49.26)$ & & \\
\hline \multicolumn{5}{|l|}{ Smoking status } \\
\hline Nonsmokers & $12,287(80.61)$ & $6000(48.83)$ & \multirow[t]{2}{*}{21.54} & \multirow[t]{2}{*}{$<0.01$} \\
\hline Smokers & $2956(19.39)$ & $1584(53.59)$ & & \\
\hline \multicolumn{5}{|l|}{ Alcohol drinking } \\
\hline Nondrinkers & $11,451(75.12)$ & $5630(49.17)$ & \multirow[t]{2}{*}{6.37} & \multirow[t]{2}{*}{0.01} \\
\hline Drinkers & $3792(24.88)$ & 1954 (51.53) & & \\
\hline \multicolumn{5}{|c|}{ Physical inactivity } \\
\hline Yes & $11,098(72.81)$ & $5737(51.69)$ & \multirow[t]{2}{*}{61.44} & \multirow[t]{2}{*}{$<0.01$} \\
\hline No & 4145 (27.19) & $1847(44.56)$ & & \\
\hline \multicolumn{5}{|l|}{ Sleep quality } \\
\hline Good & 2295 (15.06) & 735 (32.03) & \multirow[t]{3}{*}{704.34} & \multirow[t]{3}{*}{$<0.01$} \\
\hline Fair & $7347(48.20)$ & $3348(45.57)$ & & \\
\hline Poor & $5601(36.74)$ & 3501 (62.51) & & \\
\hline \multicolumn{5}{|l|}{ CES-D scores } \\
\hline$<20$ & $9818(64.41)$ & 3735 (38.04) & \multirow[t]{2}{*}{1513.55} & \multirow[t]{2}{*}{$<0.01$} \\
\hline$\geq 20$ & 5425 (35.59) & $3849(70.95)$ & & \\
\hline
\end{tabular}

the shift work $(\mathrm{OR}=1.37)$ and workplace violence $(\mathrm{OR}=1.78)$ were more likely to intend to leave.

\section{Discussion}

To our knowledge, this is the largest survey of physicians' turnover intentions in the world, and we focus on emergency physicians, a community of physicians with high levels of work stress. We found that nearly half (49.75\%) of emergency physicians had turnover intention. Compared to previous studies of psychiatrists (20\%) [23], general practitioners (47\%) [24], and emergency department nurses (23\%) [25], emergency physicians showed higher levels of turnover intention, which indicated that fully attention should be paid to this community. In addition, we identified a number of representative factors that clearly correlate with the increasing of turnover intention among emergency physicians, which could provide references for targeted measures.

\section{Age, gender, region, level of hospital and income level}

Our study found that emergency physicians who were older, male, worked in eastern China, and had high income levels were less likely to develop turnover intention. These findings are consistent with previous studies. Eastern China is economically developed, while central China and western China are relatively backward. Lu et al. [32] found that that physicians who are younger and work in under-development region had higher turnover intention because of low salaries and lack of promotion prospect. The same phenomenon also could 
Table 2 Logistic regression analysis on the influencing factors of Emergency physicians' intentions to turnover in China

\begin{tabular}{|c|c|c|c|c|c|}
\hline Variables & Coefficient & S.E & $P$ & $O R$ & $95 \% \mathrm{Cl}$ \\
\hline \multicolumn{6}{|l|}{ Gender (Ref: Female) } \\
\hline Male & -0.14 & 0.04 & 0.01 & 0.87 & $0.80-0.94$ \\
\hline \multicolumn{6}{|c|}{ Age group, y (Ref: $\leq 31)$} \\
\hline$>31$ and $\leq 37$ & -0.05 & 0.06 & 0.47 & 0.96 & $0.85-1.08$ \\
\hline$>37$ and $\leq 43$ & -0.25 & 0.08 & 0.01 & 0.78 & $0.67-0.91$ \\
\hline$>43$ & -0.45 & 0.09 & $<0.01$ & 0.64 & $0.54-0.76$ \\
\hline \multicolumn{6}{|c|}{ Region (Ref: Western China) } \\
\hline Eastern China & -0.13 & 0.04 & 0.03 & 0.88 & $0.81-0.96$ \\
\hline Central China & -0.02 & 0.05 & 0.72 & 0.98 & $0.90-1.08$ \\
\hline \multicolumn{6}{|c|}{ Education level (Ref: Associate's degree or vocational diploma) } \\
\hline Bachelor degree & 0.44 & 0.08 & $<0.01$ & 1.55 & $1.32-1.82$ \\
\hline $\begin{array}{l}\text { Master degree or } \\
\text { higher }\end{array}$ & 0.49 & 0.09 & $<0.01$ & 1.63 & $1.36-1.95$ \\
\hline \multicolumn{6}{|c|}{ Marital status (Ref: Married/widow/divorced) } \\
\hline Unmarried & 0.04 & 0.06 & 0.43 & 1.04 & $0.94-1.16$ \\
\hline \multicolumn{6}{|c|}{ Income level (Ref: Low) } \\
\hline High & -0.29 & 0.06 & $<0.01$ & 0.75 & $0.66-0.85$ \\
\hline Middle & -0.21 & 0.04 & $<0.01$ & 0.81 & $0.75-0.87$ \\
\hline \multicolumn{6}{|c|}{ Work tenure, y (Ref: $\leq 3)$} \\
\hline$>3$ and $\leq 6$ & 0.25 & 0.05 & $<0.01$ & 1.29 & $1.16-1.43$ \\
\hline$>6$ and $\leq 11$ & 0.34 & 0.06 & $<0.01$ & 1.41 & $1.26-1.58$ \\
\hline$>11$ & 0.22 & 0.06 & 0.01 & 1.25 & $1.10-1.41$ \\
\hline \multicolumn{6}{|c|}{ Contract status (Ref: Temporary) } \\
\hline Permanent & 0.01 & 0.04 & 0.75 & 1.01 & $0.93-1.10$ \\
\hline \multicolumn{6}{|c|}{ Professional title (Ref: Elementary or below) } \\
\hline Intermediate & 0.14 & 0.06 & 0.02 & 1.15 & $1.03-1.29$ \\
\hline Senior & 0.29 & 0.08 & $<0.01$ & 1.34 & $1.14-1.56$ \\
\hline \multicolumn{6}{|c|}{ Ownership (Ref: Non-governmental) } \\
\hline Governmental & -0.13 & 0.09 & 0.15 & 0.88 & $0.74-1.05$ \\
\hline \multicolumn{6}{|c|}{ Level of hospital (Ref: Other) } \\
\hline Three-grade level & -0.58 & 0.14 & $<0.01$ & 0.56 & $0.43-0.74$ \\
\hline Two-grade level & -0.34 & 0.14 & 0.02 & 0.71 & $0.54-0.94$ \\
\hline \multicolumn{6}{|l|}{ Shift work (Ref: No) } \\
\hline Yes & 0.32 & 0.06 & $<0.001$ & 1.37 & $1.22-1.55$ \\
\hline \multicolumn{6}{|c|}{ Workplace violence (Ref: No) } \\
\hline Yes & 0.58 & 0.06 & $<0.01$ & 1.78 & $1.57-2.02$ \\
\hline \multicolumn{6}{|c|}{ Self-perceived health status (Ref: Good) } \\
\hline Fair & 0.43 & 0.04 & $<0.01$ & 1.55 & $1.42-1.68$ \\
\hline Poor & 0.75 & 0.06 & $<0.01$ & 2.12 & $1.88-2.39$ \\
\hline \multicolumn{6}{|l|}{ BMI $\left(\mathrm{kg} / \mathrm{m}^{2}\right)($ Ref: $<25)$} \\
\hline$\geq 25$ & -0.07 & 0.04 & 0.09 & 0.94 & $0.87-1.01$ \\
\hline \multicolumn{6}{|c|}{ History of hypertension (Ref: No) } \\
\hline Yes & 0.04 & 0.05 & 0.52 & 1.04 & $0.93-1.15$ \\
\hline \multicolumn{6}{|c|}{ History of diabetes (Ref: No) } \\
\hline Yes & -0.12 & 0.10 & 0.22 & 0.89 & $0.74-1.07$ \\
\hline \multicolumn{6}{|c|}{ History of coronary heart disease (Ref: No) } \\
\hline Yes & 0.27 & 0.11 & 0.02 & 1.29 & $1.04-1.61$ \\
\hline \multicolumn{6}{|c|}{ Smoking status (Ref: Nonsmokers) } \\
\hline Smokers & 0.05 & 0.05 & 0.27 & 1.06 & $0.96-1.16$ \\
\hline
\end{tabular}

Table 2 (continued)

\begin{tabular}{lccccc}
\hline Variables & Coefficient & S.E & $P$ & OR & $\mathbf{9 5 \% ~ C l}$ \\
\hline $\begin{array}{l}\text { Alcohol drinking (Ref: Nondrinkers) } \\
\quad \text { Drinkers }\end{array}$ & 0.08 & 0.05 & 0.09 & 1.08 & $0.99-1.18$ \\
$\begin{array}{l}\text { Physical inactivity (Ref: No) } \\
\quad \text { Yes }\end{array}$ & -0.05 & 0.04 & 0.24 & 0.95 & $0.88-1.03$ \\
$\begin{array}{l}\text { Sleep quality (Ref: Good) } \\
\quad \text { Fair }\end{array}$ & 0.15 & 0.06 & $\mathbf{0 . 0 1}$ & 1.16 & $1.04-1.29$ \\
$\quad$ Poor & 0.36 & 0.06 & $<\mathbf{0 . 0 1}$ & 1.43 & $1.27-1.61$ \\
$\begin{array}{l}\text { CES-D Scores (Ref:<20) } \\
\quad \geq 20\end{array}$ & 1.02 & 0.04 & $<\mathbf{0 . 0 1}$ & 2.77 & $2.56-3.00$ \\
\hline
\end{tabular}

happen in lower level hospitals. While Sperlich et al. [33] reported that women are more likely to be influenced by family and social factors at work and have higher levels of work stress which is an important reason for their turnover intention [34]. In addition, some studies mention that attractive salary is the pivotal factor to increased job satisfaction and reduce turnover intention [35, 36]. Low salary can make it difficult to attract and retain new employees. Fang et al. [37] also found that the lower the salary level, the more likely physicians were to develop turnover intention. This suggests that more attention should be given to emergency doctors who are younger, female, work in less developed areas and lower level hospitals, and have poor salary.

\section{Education level, professional title and work tenure}

Previous research has shown that well-educated workers are more likely to leave for career development [38, 39]. This situation is further aggravated if career opportunities within the organization are limited [40]. We also found that highly educated emergency physicians were more likely to have turnover intention. In addition, the sense of achievement is also an important factor that affects work enthusiasm [41]. Emergency physicians with high professional titles and longer working tenure may experience a decreased sense of professional accomplishment and turnover intention. In addition, longer working tenure may lead to fatigue, tension and burnout, which has an indirect effect on the turnover intention [42]. This is consistent with our findings and indicated that the turnover intention of emergency physicians with high professional titles and long working experience should not be ignored. In reality, these community are often responsible for crucial medical serves.

\section{Health status, sleep quality, and depression}

Emergency physicians bear high physical and psychological job demands that may jeopardize their health 
status. Illness and health problems are the main causes of turnover intention [43]. Our study showed that emergency physicians with poor physical health were more likely to report turnover intention. In addition, the history of coronary heart disease is also significantly related to turnover intention. The discovery is the first reported and needs further exploration. The decline in sleep quality reflects that physicians may have higher work pressure, which is ultimately translated into turnover intention [34]. Heponiemi et al. showed a positive association between decreased sleep quality and physicians' intentions to change their profession [44]. The decline in sleep quality could lead to mood disorders, such as depression [45, 46], both of which lead to chronic fatigue. Moreover, depression may decrease concentration, which reduces the productivity of physicians and affects physicians' judgment, thus increasing occupational injury and turnover intention $[47,48]$. Therefore, the managers of health institutions should commence to improve the physical health of emergency physicians, and avoid their psychological problems, which could decline their turnover intention.

\section{Shift work and workplace violence}

Some studies have found that shift work is associated with an increase in turnover intention; moreover, reducing restrictions on working hours and providing more flexible shift work will have a positive impact on reducing turnover intention [49-51]. Our study also demonstrates that shift work increases the turnover intention among emergency physicians. On the other hand, workplace violence in emergency department has received increasing attention in recent years $[52,53]$. The survey of Occupational Health Safety Network (OHSN) in America during 2012-2015 showed the incidence of emergency room violence was $19.3 \%$, with an average annual growth rate of $23 \%$ [54]; and previous studies have shown that only $30 \%$ of cases were documented $[55,56]$, while nearly $80 \%$ of cases was undocumented [57]. Heponiemi et al. [58] reported workplace violence in the health care sector may lead to increased turnover and job dissatisfaction, which is consistent with our findings. Therefore, targeted measures are needed to optimize the health service system, provide more flexible working regimes for emergency physicians, and mitigate doctor-patient relationships to reduce workplace violence.

It is worth noting that among the factors identified, some are "push" factors (e.g., violence, poor health and shift work) and others are "pull" factors (e.g., ambition and career development). Comprehensive measures could reduce turnover intention more effectively. In the process of developing targeted measures, the government and medical institutions should pay more attention to eliminating the negative impact of "push" factors and improving the retention rate. Moreover, for the "pull" factor, it is important to provide sufficient development opportunities for physicians. Proper turnover is acceptable.

The shortage of physicians is the focus of the current medical service field, but there is no effective solution to this problem. It might be a potential direction to commence by reducing turnover intention. This study is based in China, the largest developing country. Currently, many countries have the similar incomplete medical service system, and are also faced with excessive medical demand. This contradiction is particularly evident in the global COVID-19 pandemic and also creates a higher workload for physicians, especially emergency physicians. Therefore, researching the prevalence and influencing factors of turnover intention of emergency physicians in China will provide a valuable reference for researchers and policy makers of the global emergency health service system.

\section{Strengths, limitations and future suggestions}

Our study used a large-sample cross-sectional survey to explore the influencing factors of turnover intention among emergency physicians. First, the large sample size significantly increased the statistical power. We surveyed nearly a quarter of the nation's emergency physicians, so the participants was representative. Second, this study included more than twenty potential contributors and produced many valuable findings, which reflects their working status and presented a broad view of the challenges faced by emergency physicians. Third, the survey was anonymous and self-administered, which likely made the respondents provide more valid responses and eliminated interviewer bias.

This study had several limitations. First, the study used a cross-sectional study design, which precluded the evaluation of the temporality of the observed relationships. Second, the data were collected from the participants' self-reports; thus, recall bias was unavoidable. Finally, the study was performed before the COVID-19 pandemic, which may have led to changes in the turnover intention of emergency physicians after the pandemic.

Based on our findings, we suggest that, first, prospective studies are needed to investigate the association between the identified factors and turnover intention. Further research should also conducted into the postturnover whereabouts of emergency physicians. Second, this study highlights the need for the investigation or implementation of interventions to improve emergency physicians' well-being or promote strategies to reduce work pressure on healthcare settings. Finally, investigating the potential impact of turnover intention 
on emergency physicians' work performance, the quality of patient care delivery, and family life would provide important insights.

\section{Conclusion}

Our study found that nearly half of emergency physicians in China have turnover intention which is influenced by a variety of factors. Targeted intervening measures should be taken to reduce the turnover intention, so as to avoid the shortage of physicians and thus hinder the supply of emergency medical services.

\section{Abbreviations}

BMI: Body Mass Index; CES-D: Center for Epidemiological Studies-Depression Scale.

\section{Acknowledgements}

We would like to thank the study participants and all staff members involved in this study for their efforts in the data collection.

\section{Authors' contributions}

SJY, XS, YG and CZL conceived and designed the study. SJY, XS, RXW, ZQL, XYS, and QZ participated in the acquisition of data. XS analyzed the data. XYS gave advice on methodology. SJY and XS drafted the manuscript, and SJY, XS, XYS, WNF, XTH, YG and CZL revised the manuscript. CZL is the guarantors of this work and had full access to all the data in the study and takes responsibility for its integrity and the accuracy of the data analysis. All authors read and approved the final manuscript.

\section{Funding}

This study was supported by the National Natural Science Foundation of China (82160647) and the Hainan Provincial Key Research and Development Project (ZDYF2020112).

\section{Availability of data and materials}

Data may be made available by contacting the corresponding author.

\section{Declarations}

\section{Ethics approval and consent to participate}

The study was approved by the Institutional Ethics Board of the Second Affiliated Hospital of Hainan Medical University, Haikou, China (HYLL-2018-035) and the study team obtained informed consent from all participants. Participants were made aware that they could withdraw at any time.

\section{Consent for publication}

All authors consent to publish this article.

\section{Competing interests}

We declare that we have no conflict of interests.

\footnotetext{
Author details

${ }^{1}$ School of Public Health, Hainan Medical University, Haikou, Hainan, China. ${ }^{2}$ Key Laboratory of Emergency and Trauma of Ministry of Education, Hainan Medical University, Haikou, Hainan, China. ${ }^{3}$ Department of Social Medicine and Health Management, School of Public Health, Tongji Medical College, Huazhong University of Science and Technology, No. 13 Hangkong Road, Wuhan 430030, Hubei, China. ${ }^{4}$ Department of Emergency, Hainan Clinical Research Center for Acute and Critical Diseases, The Second Affiliated Hospital of Hainan Medical University, Haikou, Hainan, China. ${ }^{5}$ Emergency and Trauma College, Hainan Medical University, Haikou, Hainan, China. ${ }^{6}$ Research Unit of Island Emergency Medicine, Chinese Academy of Medical Sciences (No. 2019RU013), Hainan Medical University, Haikou, Hainan, China. ${ }^{7}$ Department of Emergency Medicine, Hunan Provincial Institute of Emergency Medicine, Hunan Provincial Key Laboratory of Emergency and Critical
}

Care Metabolomics, Hunan Provincial People's Hospital/The First Affiliated Hospital, Hunan Normal University, Changsha, Hunan, China. ${ }^{8}$ Department of Emergency Medicine Center, Sichuan Provincial People's Hospital, University of Electronic Science and Technology of China, Chengdu, China.

Received: 27 July 2021 Accepted: 4 November 2021

Published online: 04 December 2021

\section{References}

1. Nancarrow S, Bradbury J, Pit SW, Ariss S. Intention to stay and intention to leave: are they two sides of the same coin? A cross-sectional structural equation modelling study among health and social care workers. J Occup Health. 2014;56(4):292-300.

2. Hann M, Reeves D, Sibbald B. Relationships between job satisfaction, intentions to leave family practice and actually leaving among family physicians in England. Eur J Public Health. 2011;21(4):499-503.

3. Schwarzkopf D, Rüddel H, Thomas-Rüddel DO, Felfe J, Poidinger B, Matthäus-Krämer CT, et al. Perceived nonbeneficial treatment of patients, burnout, and intention to leave the job among ICU nurses and junior and senior physicians. Crit Care Med. 2017;45:3.

4. Stone PW, Larson EL, Mooney-Kane C, Smolowitz J, Lin SX, Dick AW. Organizational climate and intensive care unit nurses' intention to leave*. Crit Care Med. 2006;34:7.

5. Degen C, Li J, Angerer P. Physicians' intention to leave direct patient care: an integrative review. Hum Resour Health. 2015;13:74.

6. Heponiemi T, Kouvonen A, Vänskä J, Halila H, Sinervo T, Kivimäki M, et al. The association of distress and sleeping problems with physicians' intentions to change profession: the moderating effect of job control. J Occup Health Psychol. 2009;14(4):365-73.

7. Kankaanranta T, Nummi T, Vainiomäki J, Halila H, Hyppölä H, Isokoski M, et al. The role of job satisfaction, job dissatisfaction and demographic factors on physicians' intentions to switch work sector from public to private. Health policy. 2007;83(1):50-64.

8. Masselink LE, Lee SY, Konrad TR. Workplace relational factors and physicians' intention to withdraw from practice. Health Care Manage Rev. 2008;33(2):178-87.

9. Sheldon GF, Ricketts TC, Charles A, King J, Fraher EP, Meyer A. The global health workforce shortage: role of surgeons and other providers. Adv Surg. 2008;42:63-85.

10. Toyabe S. Trend in geographic distribution of physicians in Japan. Int J Equity Health. 2009;8:5.

11. Iglehart JK. A new day dawns for workforce redesign. Health Aff (Millwood). 2013;32(11):1870.

12. Sklar DP. How many doctors will we need? A special issue on the physician workforce. Acad med. 2013;88(12):1785-7.

13. Buchbinder SB, Wilson M, Melick CF, Powe NR. Estimates of costs of primary care physician turnover. Am J Manag Care. 1999;5(11):1431-8.

14. Plomondon ME, Magid DJ, Steiner JF, MaWhinney S, Gifford BD, Shih SC, et al. Primary care provider turnover and quality in managed care organizations. Am J Manag Care. 2007;13(8):465-72.

15. Firth-Cozens J, Greenhalgh J. Doctors' perceptions of the links between stress and lowered clinical care. Soc Sci Med. 1997;44(7):1017-22.

16. Misra-Hebert AD, Kay R, Stoller JK. A review of physician turnover: rates, causes, and consequences. Am J Med Qual. 2004;19(2):56-66.

17. Johnston A, Abraham L, Greenslade J, Thom O, Carlstrom E, Wallis M, et al. Review article: Staff perception of the emergency department working environment: Integrative review of the literature. Em Med Australas. 2016;28(1):7-26.

18. Pan C, Pang J, Cheng K, Xu F, Chen Y. Trends and challenges of emergency and acute care in Chinese mainland: 2005-2017. World J Em Med. 2021;12(1):5-11.

19. Song X, Fu W, Liu X, Luo Z, Wang R, Zhou N, et al. Mental health status of medical staff in emergency departments during the Coronavirus disease 2019 epidemic in China. Brain Behav Immun. 2020;88:60-5.

20. Zhou H, Li C, Yan Y. The emergency department in China: status and challenges: British Association for Accident and Emergency Medicine; 2014. p. 85-6.

21. Arora M, Asha S, Chinnappa J, Diwan AD. Review article: burnout in emergency medicine physicians. Emerg Med Australas. 2013;25(6):491-5. 
22. Bragard I, Dupuis G, Fleet R. Quality of work life, burnout, and stress in emergency department physicians: a qualitative review. Eur J Emerg Med. 2015;22(4):227-34

23. Jiang F, Zhou H, Rakofsky J, Hu L, Liu T, Wu S, et al. Intention to leave and associated factors among psychiatric nurses in China: a nationwide crosssectional study. Int J Nurs Stud. 2019;94:159-65.

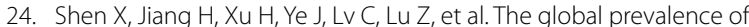
turnover intention among general practitioners: a systematic review and meta-analysis. Bmc Fam Pract. 2020;21(1):246.

25. Jiang H, Ma L, Gao C, Li T, Huang L, Huang W. Satisfaction, burnout and intention to stay of emergency nurses in Shanghai. Emerg Med J. 2017;34(7):448-53.

26. Wang PX, Wang MZ, Hu GX, Wang ZM. Study on the relationship between workplace violence and work ability among health care professionals in Shangqiu City. Wei Sheng Yan Jiu. 2006;35(4):472-4.

27. Cosco TD, Lachance CC, Blodgett JM, Stubbs B, Co M, Veronese N, et al. Latent structure of the Centre for Epidemiologic Studies Depression Scale (CES-D) in older adult populations: a systematic review. Aging Ment Health. 2020;24(5):700-4.

28. Dozeman E, van Schaik DJ, van Marwijk HW, Stek ML, van der Horst HE, Beekman AT. The center for epidemiological studies depression scale (CES-D) is an adequate screening instrument for depressive and anxiety disorders in a very old population living in residential homes. Int J Geriatr Psychiatry. 2011;26(3):239-46.

29. Cheng ST, Chan AC. The Center for Epidemiologic Studies Depression Scale in older Chinese: thresholds for long and short forms. Int J Geriatr Psychiatry. 2005;20(5):465-70.

30. Vilagut G, Forero CG, Barbaglia G, Alonso J. Screening for depression in the general population with the center for epidemiologic studies depression (CES-D): a systematic review with meta-analysis. PLoS ONE. 2016;11(5):e155431.

31. Jiang L, Wang Y, Zhang Y, Li R, Wu H, Li C, et al. The Reliability and Validity of the Center for Epidemiologic Studies Depression Scale (CES-D) for Chinese University Students. Front Psychiatry. 2019;10:315.

32. Lu Y, Hu XM, Huang XL, Zhuang XD, Guo P, Feng LF, et al. The relationship between job satisfaction, work stress, work-family conflict, and turnover intention among physicians in Guangdong, China: a cross-sectional study. BMJ Open. 2017;7(5):e14894.

33. Sperlich S, Geyer S. The impact of social and family-related factors on women's stress experience in household and family work. Int J Public Health. 2015;60(3):375-87.

34. Wong CA, Spence LH. The influence of frontline manager job strain on burnout, commitment and turnover intention: a cross-sectional study. Int J Nurs Stud. 2015;52(12):1824-33.

35. Shields MA, Ward M. Improving nurse retention in the National Health Service in England: the impact of job satisfaction on intentions to quit. J Health Econ. 2001;20(5):677-701.

36. Zhang $Y$, Feng $X$. The relationship between job satisfaction, burnout, and turnover intention among physicians from urban state-owned medical institutions in Hubei, China: a cross-sectional study. BMC Health Serv Res. 2011;11:235.

37. Fang $P$, Liu $X$, Huang $L$, Zhang $X$, Fang Z. Factors that influence the turnover intention of Chinese village doctors based on the investigation results of Xiangyang City in Hubei Province. Int J Equity Health. 2014;13:84.

38. Hayes LJ, O'Brien-Pallas L, Duffield C, Shamian J, Buchan J, Hughes F, et al. Nurse turnover: a literature review. Int J Nurs Stud. 2006;43(2):237-63.

39. Aiken LH, Buchan J, Sochalski J, Nichols B, Powell M. Trends in international nurse migration. Health Aff (Millwood). 2004;23(3):69-77.

40. Price JL, Mueller CW. Professional turnover: the case of nurses. Health Syst Manage. 1981;15:1-160.

41. Colindres CV, Bryce E, Coral-Rosero P, Ramos-Soto RM, Bonilla F, Yassi A. Effect of effort-reward imbalance and burnout on infection control among Ecuadorian nurses. Int Nurs Rev. 2018;65(2):190-9.

42. Herda DN, Lavelle JJ. The auditor-audit firm relationship and its effect on burnout and turnover intention. Account Horiz. 2012;26(4):707-23.

43. Ki J, Ryu J, Baek J, Huh I, Choi-Kwon S. Association between health problems and turnover intention in shift work nurses: health problem clustering. Int J Env Res Pub He. 2020;17(12):4532.

44. Heponiemi T, Kouvonen A, Vänskä J, Halila H, Sinervo T, Kivimäki M, et al. The association of distress and sleeping problems with physicians' intentions to change profession: the moderating effect of job control. J Occup Health Psychol. 2009;14(4):365-73.

45. Zhai L, Zhang H, Zhang D. Sleep duration and depression among adults: a meta-analysis of prospective studies. Depress Anxiety. 2015;32(9):664-70.

46. Ferri P, Guadi M, Marcheselli L, Balduzzi S, Magnani D, Di Lorenzo R. The impact of shift work on the psychological and physical health of nurses in a general hospital: a comparison between rotating night shifts and day shifts. Risk Manag Healthc Policy. 2016;9:203-11.

47. Mata DA, Ramos MA, Bansal N, Khan R, Guille C, Di Angelantonio E, et al. Prevalence of depression and depressive symptoms among resident physicians: a systematic review and meta-analysis. JAMA. 2015;314(22):2373-83.

48. Levis B, Azar M, Thombs BD. Resident physicians with depression or depressive symptoms. JAMA. 2016;315(21):2347.

49. Rambur B, Palumbo MV, Mclntosh B, Mongeon J. A statewide analysis of RNs' intention to leave their position. Nurs Outlook. 2003;51(4):182-8.

50. Yin JC, Yang KP. Nursing turnover in Taiwan: a meta-analysis of related factors. Int J Nurs Stud. 2002;39(6):573-81.

51. Shader K, Broome ME, Broome CD, West ME, Nash M. Factors influencing satisfaction and anticipated turnover for nurses in an academic medical center. J Nurs Adm. 2001;31(4):210-6.

52. Ramacciati N, Ceccagnoli A, Addey B, Lumini E, Rasero L. Violence towards emergency nurses: a narrative review of theories and frameworks. Int Emerg Nurs. 2018;39:2-12.

53. Zafar W, Siddiqui E, Ejaz K, Shehzad MU, Khan UR, Jamali S, et al. Health care personnel and workplace violence in the emergency departments of a volatile metropolis: results from Karachi Pakistan. J Emerg Med. 2013:45(5):761-72

54. Groenewold MR, Sarmiento R, Vanoli K, Raudabaugh W, Nowlin S, Gomaa A. Workplace violence injury in 106 US hospitals participating in the Occupational Health Safety Network (OHSN), 2012-2015. Am J Ind Med. 2018;61(2):157-66.

55. Erickson L, Williams-Evans SA. Attitudes of emergency nurses regarding patient assaults. J Emerg Nurs. 2000;26(3):210-5.

56. Partridge B, Affleck J. Verbal abuse and physical assault in the emergency department: Rates of violence, perceptions of safety, and attitudes towards security. Australas Emerg Nurs J. 2017;20(3):139-45.

57. Pinar R, Ucmak F. Verbal and physical violence in emergency departments: a survey of nurses in Istanbul. Turkey J Clin Nurs. 2011;20(3-4):510-7.

58. Heponiemi T, Kouvonen A, Virtanen M, Vänskä J, Elovainio M. The prospective effects of workplace violence on physicians'job satisfaction and turnover intentions: the buffering effect of job control. BMC Health Serv Res. 2014;14:19.

\section{Publisher's Note}

Springer Nature remains neutral with regard to jurisdictional claims in published maps and institutional affiliations.

Ready to submit your research? Choose BMC and benefit from

- fast, convenient online submission

- thorough peer review by experienced researchers in your field

- rapid publication on acceptance

- support for research data, including large and complex data types

- gold Open Access which fosters wider collaboration and increased citations

- maximum visibility for your research: over 100M website views per year

At BMC, research is always in progress.

Learn more biomedcentral.com/submissions 